\title{
E-COHESION MATURITY: HOW TO MEASURE THE EFFICIENCY OF DIGITAL COHESION POLICY
}

\author{
Tamás Laposa ${ }^{1}$
}

\begin{abstract}
This paper focuses on the maturity of e-government services on the domain of European fund management, to explore the measurability of potential efficiency gains.

The practical relevance of the topic is that the current European legislation prescribes that Member States shall offer electronic fund management services to beneficiaries to foment the efficient use of European Structural and Investment Funds. The main driver of this concept is the reduction of administrative burdens which can be achieved by the Europe-wide utilization of paperless fund management tools and by harnessing the interoperability of information systems. In the scientific discourse, the above concept is labelled as "e-Cohesion". However, the legislation sets quite broad requirements for its implementation, so the e-Cohesion landscape and the intended efficiency gains may appreciably differ from country to country. The exploration of this "digital efficiency divide" offers a new relevant research opportunity. Therefore, this article is dealing with the measurability of efficiency of e-tools to methodologically support Member States in the realization and fine-tuning of their national e-Cohesion concepts.
\end{abstract}

It is presented in this paper that the level of potential efficiency gains is connected to e-government readiness, i.e. the maturity of e-Cohesion systems. The paper, therefore, systematically reviews the relevant e-Government literature on the issue of maturity. Based on this, it aims to identify the most important models and methodological elements which address the main attributes of e-Cohesion to pave the way for further empirical research and the creation of an e-Cohesion-specific maturity model.

\section{Introduction}

According to Regulation (EU) No 1303/2013 of the European Parliament and of the Council the EU provides funds for EU Member States through multi-annual development programmes in order to implement the Union strategy for smart, sustainable and inclusive growth, as well as the Fundspecific objectives including economic, social and territorial cohesion. Pursuant to the legislation arrangements for the implementation and use of the funds shall take into account the overall aim of reducing the administrative burdens on beneficiaries and bodies involved in the management and control of the programmes. [11]

With regard to these provisions, the Commission started the e-Cohesion initiative to contribute to the reduction of administrative burdens and the effective implementation of the funds. E-Cohesion is a set of procedural, legal, technological and organisational components to support the provision of effective e-Government services. However the maximisation of efficiency gains depends on the decisions of Member States, since the European legislation sets minimum requirements for electronic services. As proven by the study of the European Commission and Deloitte, efficiency

\footnotetext{
${ }^{1}$ National University of Public Administration, Budapest
} 
gains can be realized at different levels and the rate of improvements can be significant. [10] This paper attempts to show that the progress made could be best described with the methodology of maturity models. The maturity of e-Cohesion and the targeted efficiency gains are influenced by a wider range of attributes than addressed in the above model. Moreover there is no specific maturity model that can address the complexity of these attributes.

This paper has three main aims: first, to review the methodology of maturity models and those models relevant from the perspective of e-Cohesion; second, to identify the main measurable attributes of e-Cohesion and the relevant maturity models addressing them; and third, to make proposals for further research and the elaboration of an e-Cohesion-specific maturity model.

\section{The methodology of maturity models}

Lahrmann et al. defines maturity as "the state of being complete, perfect or ready" where this stage can be achieved by an evolutionary progress from an initial stage to an end stage. [14] The concept of maturity measurement was published by the Software Engineering Institute (SEI) - Carnegie Mellon with the introduction of the Capability Maturity Model (CMM). [6] Reviewing the relevant papers, it can be found that more than a hundred of different models on different domains have been created since. [4] In this section, the role and typology of maturity models are explained in detail to develop a better understanding on its methodological background.

\subsection{The role of maturity models}

Caralli et al. defines a maturity model as a set of characteristics, attributes, indicators or patterns representing progress in a particular domain or discipline. These models help organizations to evaluate and benchmark their practices, processes and methods against a clear set of standards or best practices of the given domain or discipline. Organizations can apply maturity models to define their current level of maturity and then determine the expected path of improvement [19]

According to Bruin et al. maturity models are evaluative tools to assess and increase the maturity (competency, capability, level of sophistication) of a specific domain on the basis of an agreed set of criteria. [6]

A maturity model represents a desired evolution path for organisations or processes as discrete stages (a sequence of maturity levels). [4] The most frequently-used way of evaluation is a fivepoint Likert scale where Level 5 represents the highest level. [6] Levels represent the transitional states in the model, they describe evolutionary steps or express a measurable attribute. Attributes are the core model components that appear on each level. They are based on best practices or standards expressed as characteristics, indicators or processes. [19]

In the model organisations or processes advance between an initial stage and a final stage that represents total maturity. During this advancement the capabilities of the organisations or their process performance progresses evolutionarily. The maturity model is a tool to determine the position of the organisation or the process on the evolution path by providing criteria and characteristics to be fulfilled to reach a particular maturity level. [4] 


\subsection{Typology of maturity models}

Reviewing the constituent literature, it can be noticed that maturity models focus on different maturity factors such as process maturity (to which extent a specific process is defined, managed, measured, controlled, and effective), object maturity (level of sophistication of a software or a machine) and people capability (ability of knowledge creation and proficiency enhancement). From the perspective of maturity factors models can be one-dimensional or they can address different factors at the same time. [17]

As to the nature of maturity assessment models they can be descriptive, prescriptive or comparative. A descriptive model is simply used for the assessment of the current state of play i.e. the as-is situation without any provisions for further improvement of maturity. A prescriptive model focuses on maturity improvement and enables the elaboration of an improvement roadmap on a specific domain. A comparative model enables benchmarking across different organisations, industries or regions. [6]

Concerning the structure of maturity stages, fixed-level and focus area maturity models can be distinguished. Fixed-level models consist of generic maturity levels and they are well-suited to assessment and benchmarking of organizations. In many cases, these models cannot capture the interdependencies of the different processes that need to be improved in a specific domain. Focus area maturity models identify focus areas that need to be developed and the distinct focus areas have a different evolution path i.e. the number of development stages can vary from area to area. These models enable a more balanced and incremental improvement by helping organisations to address the complexity of the factors determining the effectiveness of a specific domain. [5]

\subsection{E-Government maturity models}

Maturity models are widely used in the domain of e-Government. From a scientific perspective, the most cited models are - for instance - the Layne and Lee [16] and the Andersen and Henriksen [2] models.

The Layne and Lee model is one of the earliest models to measure the structural transformation of public services. The four-stage model helps governments planning the introduction of Internetbased government models and the model supports the measurement of technological-organizational complexity and the integration of e-Government services. [16]

Andersen and Henriksen argue that models as Layne and Lee approach digital services from the perspective of technology integration by predominantly focusing on issues as information quality, efficiency, and effectiveness. The authors propose to refocus e-Government models on the front-end of government and the benefits of end-users by measuring activity and customer centricity. [2]

\section{The e-Cohesion concept}

\subsection{Reduction of administrative burdens - the creation of the e-Cohesion concept}

In 2010, the European Commission initiated an Action Programme to simplify administrative requirements and eliminate unnecessary administrative burdens on businesses, small businesses in particular. The Action Programme identified 13 priority areas for administrative burden reduction, where Cohesion policy was one of the priority areas with an estimated $24 \%$ reduction of 
administrative costs. [7] Experts argued that the above reduction could be realised by the provision of interactive portal services, where beneficiaries can submit all necessary information digitally. The introduction of online portal facilities could minimise multiple information requests and reduce the scope of paper-based information obligations. These measures contribute to the improvement of efficiency which is the main driver of the reduction of burdens.

Following the above recommendations, the Commission launched an initiative, focused on the reduction of administrative burdens of cohesion policy and also rural development policy by the provision of electronic data exchange services via online portals. The initiative was labelled as " $e$ Cohesion" addressing a wide range of legal, procedural, organisational and Member State-specific factors. E-Cohesion is not simply an IT issue. It is a framework of specific components to reduce administrative burdens via the implementation of e-Government services. [9]

To ensure the expected level of efficiency, the Commission included the requirements of the eCohesion concept in the legal provisions of funding in the 2014-2020 period. Regulation (EU) No $1303 / 2013$ of the European Parliament and of the Council specifies the three fundamental components of e-Cohesion: the provision of electronic data exchange services, interoperability of systems and the implementation of the only once encoding principle.

The digital nature of the new funding procedures requires specific conditions to guarantee the quality, effectiveness and the authenticity of services. For this reason the fundamental components need to be supplemented by additional components, such as e-signature, e-document management and $\boldsymbol{e}$-audit. Their main requirements are regulated by Commission Implementing Regulations (EU) No 821/2014 and No 1011/2014. [15]

\subsection{The components of e-Cohesion}

\subsubsection{Electronic data exchange}

Member States shall ensure that all exchanges of information between beneficiaries with a grant agreement and the relevant authorities can be carried out by means of electronic data exchange systems.

Taking into consideration the specificities of national regulations, the European legislation leaves it to the Member States to make the use of e-Cohesion compulsory or optional to clients. It is also up to the Member States whether they provide electronic services for only beneficiaries or they make these services available to applicants applying for a grant as well. The expanding use of financial instruments - particularly when those are combined with grants - brings a new area with some specific features where the interpretation of e-Cohesion is to be addressed. [3]

Taking into consideration the full-electronic nature of procedures, the legislation sets specific technological requirements (security, system availability, data integrity, data protection and privacy, methods of authentication and the minimum functionality of electronic portals) to guarantee the quality of services and the efficiency of procedures. [12]

\subsubsection{The "only once encoding" principle and interoperability}

Data and documents regarding a single development project shall be shared and re-used by the authorities involved in the management of the same development programme. The relevant 
authorities cannot ask for the same data repeatedly. The application of the principle is strongly interlinked with interoperability. [12]

Interoperability can be defined as "the ability of disparate and diverse organisations to interact towards mutually beneficial and agreed common goals, involving the sharing of information and knowledge between the organisations, through the business processes they support, by means of the exchange of data between their respective ICT systems". Henceforth, interoperability is not simply a technological issue. It requires the cooperation of authorities at legal, organisational, semantic and technical levels. $[12,8]$

As a prerequisite of the principle, the regulation sets the cooperation of authorities at development programme level as a minimum requirement. These measures avoid multiple data requests at programme level but it leaves the possibility open for Member States to manage different programmes in separate IT systems. [12]

\subsubsection{E-signature}

As electronic data exchange transactions are carried out digitally an adequate level of authentication is required to guarantee the veracity of transactions. The regulation sets internationally-accepted standards stating that transactions shall bear an electronic signature compatible with one of the three types of electronic signature defined by Regulation (EU) No 910/2014 of the European Parliament and of the Council. The required level of authentication depends on national laws and requirements on verification and audit. [12]

\subsubsection{E-document management}

The digitalisation of procedures changes the nature of document submission and management. This requirement has both procedural and technological implications. From one side, the accepted data carriers and the compliance criteria of digital documents shall be laid down by national authorities, on the basis of national legal requirements and audit standards. From the other side, IT systems shall be equipped with adequate document management capabilities and they shall meet accepted security standards to ensure the compliance of electronic documents with national requirements. $[11,13]$

\subsubsection{Electronic audit}

In certain cases, national audit and verification requirements and the paperless business procedures might be in conflict, so the concept of e-Cohesion needs to bring them in balance by providing guarantees for the compliance of documents and data while still enabling digital submission. For this reason, the legislation defines that digital documents are reliable sources for audits and financial verification if they have been submitted via the electronic data exchange system. This provision is based on the previously mentioned requirement that electronic data exchange systems need to meet national legal requirements, compliance rules and security standards. [12]

\subsection{The maturity of e-Cohesion}

The European legislation sets minimum requirements that ensure the expected efficiency gains, but the requirements need to be adapted to national specificities and further particularized by national legislation. [12] It is the decision of each Member State to adopt the minimum framework of 
requirements or to go beyond them. This means that the e-Cohesion solution and the level of total efficiency gains may differ from country to country.

If a country decides to go beyond the minimum requirements of e-Cohesion and applies more mature solutions they can reach a higher level of efficiency. Thus, efficiency has different stages that can be achieved according to the decisions of Member States. The Commission and Deloitte elaborated a maturity model to measure the sophistication of e-Cohesion portal functionalities and potential efficiency gains. Based on this model an annual $8 \%$ of administrative burden reduction could be estimated, if the highest level of portal sophistication would be implemented in all EU Member States. [10] The schematics of this maturity model are shown in Figure 1.

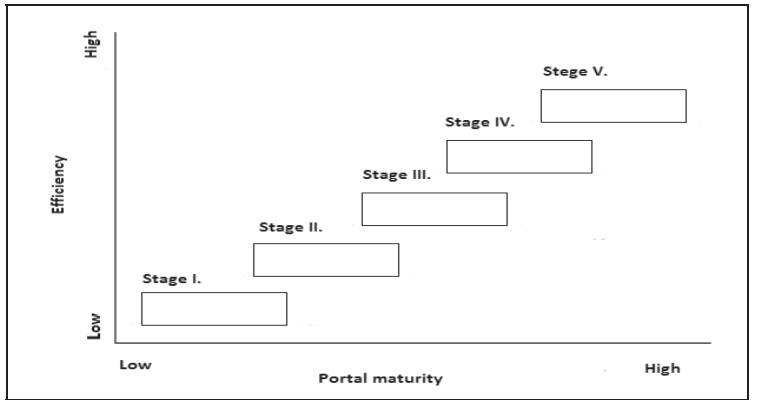

Figure 1: The schematics of the current e-Cohesion maturity model

The above model provides a good roadmap for Member States to plan the development of eCohesion portals but it dominantly focuses on the functionality of e-portals. Further attributes can be found, which significantly contribute to the efficiency of e-Cohesion concepts. It is reasonable to assume that the success of e-Cohesion is influenced by a wider range of attributes. Therefore the upcoming section is dealing with the identification of e-Cohesion attributes to help understanding the complexity of e-Cohesion maturity.

\section{Attributes of e-Cohesion}

The first thing to be considered is that maturity is based on the progression of certain measurable attributes that are specific to the relevant domain. In this section, the main attributes of e-Cohesion influencing efficiency are to be identified. Primarily, the concept of e-Cohesion defines six components setting the minimum requirements of implementation. It should be further analysed to what extent these components exert influence on its maturity. Furthermore, e-Cohesion is an eGovernment project so the relevant literature on the maturity of e-Government portals will be reviewed as well. [15]

\section{1 e-Cohesion-specific factors}

The concept of e-Cohesion defines six components (electronic data exchange, only once encoding, interoperability, e-signature, e-document management and electronic audit) which are summarized in the below table: 


\begin{tabular}{|c|c|c|}
\hline Component & Requirement No. & Minimum requirements \\
\hline Electronic data exchange & 1. & security and availability \\
\hline Electronic data exchange & 2. & data protection and privacy \\
\hline Electronic data exchange & 3. & data integrity \\
\hline Electronic data exchange & 4. & minimum functionality of portals \\
\hline Electronic data exchange & 5. & no repeated data request by different authorities at development programme level \\
\hline Only once encoding & 6. & cooperation of relevant authorities at development programme level \\
\hline Interoperability & 7. & authentication with one of the three types of electronic signatures \\
\hline E-signature & 8. & electronic document management systems with an adequate level of security \\
\hline E-document management & 9. & adequate level of security of the electronic system \\
\hline Electronic audit & 10. & 1.
\end{tabular}

Table 1: minimum requirements of e-Cohesion components

The analysis reveals that most of the above requirements (No. 1.-4. and 8.-10.) are connected to the sound electronic management (security, integrity, authenticity, privacy, availability) of data and documents instead of focusing on the efficiency of procedures and the reduction of administrative burdens. Therefore, these requirements are not connected to the maturity of e-Cohesion in the scope of this research.

In terms of portal functionality (No. 5) Commission Implementing Regulation (EU) No 1011/2014 prescribes that electronic data exchange systems shall be equipped with at least the following functionalities: interactive forms and/or forms prefilled by the system, automatic calculations, automatic embedded controls which reduce repeated exchanges of documents or information, system-generated alerts, online status tracking. [12] These functions are directly linked to the reduction of burdens and the issue of efficiency. However Member States can add further functions to improve the level of maturity, so this requirement has a direct influence on efficiency gains as it is addressed by the available model of the Commission and Deloitte.

The principle of only once encoding (No. 6 and 7) and interoperability are strongly interrelated and their higher level of maturity can also increase efficiency. Their minimum requirements ensure efficiency gains within the limit of a single development programme. Here the efficiency of fund management can be further extended if a Member State applies these components for all development programmes. In case of interoperability, system connections to national databases and the automatic retrieval of relevant beneficiary data can further improve efficiency. These factors are proposed to be addressed by the e-Cohesion maturity model.

\subsection{General e-Government related factors}

Upon reviewing the relevant papers, it can be concluded that a wide range of pertinent models are available in the scientific literature. The paper of Abdoullah Fath-Allah et al. compares the similarities and differences of 25 e-Government maturity models among others with regard to the main attributes of these models. [1] These attributes provide further measurement criteria on the maturity of portals, so the paper contains important inputs from the perspective of this research. The following table recapitulates the above attributes to help analysing their relevance for e-Cohesion: 


\begin{tabular}{|c|c|}
\hline Attributes & Definition \\
\hline One stop shop & The e-portal is a single point of entry for all e-government services. \\
\hline Customer centricity & The services or the e-portal are designed from a citizens' perspective and not from an institutional one. \\
\hline Personalization & Citizens can personalize and customize the e-portal's functionalities according to their needs. \\
\hline Interoperability & Cooperation of government agencies to work together and exchange information. \\
\hline Payment & Citizens can pay in the e-portal via credit/debit cards. \\
\hline E-participation & Involvement of the citizens in the e-government process using comment forms, surveys, e-voting. \\
\hline
\end{tabular}

Table 2: main features of e-Government maturity models [1]

E-Cohesion does not restrict the usage of separate IT systems for the management of different programmes. This means there can be more than one e-Cohesion portal in a Member State. In this situation beneficiaries might need to use different portals for different types of projects which can complicate the administration of projects compared to the usage of a single e-portal for all funds. Hence the principle of one stop shop can place e-Cohesion portals on a higher level of maturity.

As proven by empirical research the complex relationship of technology and society requires a special attention in public sector IT projects. [18] Usability and user-orientation are crucial factors in creating added value to citizens and making administrative arrangements easier, so customer centricity and personalization have an undoubted impact on the efficiency of e-Cohesion.

As regards interoperability its importance has already been covered in the former subsection. In terms of payment beneficiaries do not need to effect financial transactions via the e-Cohesion portal, so this feature has no relevance.

In the reviewed models, e-participation mainly focuses on portal functions facilitating the political involvement of citizens. From this perspective e-participation has no relevance for e-Cohesion. From another point of view, e-portals can offer further functions that extend the limits of involvement of beneficiaries in administrative procedures. E-Cohesion is focused on the electronic exchange of formal information. Nonetheless beneficiaries often contact the authorities with informal questions regarding their administrative tasks or the usage of certain functions. Thus, portal features facilitating informal communication between authorities and beneficiaries can channel all information exchanges in one platform which can have a positive impact on the efficiency of e-Cohesion.

\section{The maturity of e-Cohesion}

After the analysis of attributes, the goal of this paper is to identify the most important maturity models in the pertinent literature that address the above factors. Based on the analysis areas for further research and the creation of an e-Cohesion-specific maturity model covering all relevant attributes are also proposed.

\subsection{Review of e-Government maturity models}

In the former section seven attributes (portal functionality, only once encoding, interoperability, one stop shop, customer centricity, personalization, e-participation) were identified which are relevant in the respect of the maturity of e-Cohesion. For the identification of pertinent models the findings of Abdoullah Fath-Allah et al. were used, comparing 25 relevant models and the study of the Commission and Deloitte which contains a maturity model on one of the e-Cohesion 
requirements namely the functionality of e-Cohesion portals. [1, 10] Reviewing the above documents the next models were identified:

\begin{tabular}{|c|c|c|c|c|c|c|c|c|}
\hline & Functionality & $\begin{array}{l}\text { Only once } \\
\text { encoding }\end{array}$ & Interoperability & One stop shop & $\begin{array}{l}\text { Customer- } \\
\text { centricity }\end{array}$ & Personalization & Participation & Sum \\
\hline Accenture & & & $x$ & & $x$ & & $x$ & 3 \\
\hline Alhomod et al. & & & $x$ & & & & & 1 \\
\hline Almazan and Gil-Garcia & & & $x$ & $x$ & $x$ & $x$ & $x$ & 5 \\
\hline Andersen and Henriksen & & & $x$ & & $x$ & $x$ & & 3 \\
\hline Chandler and Emanuel & & & $x$ & & & & & 1 \\
\hline Chen et al. & & & $x$ & & & & & 1 \\
\hline Cisco & & & $x$ & & & $x$ & $x$ & 3 \\
\hline Commission, Deloitte & $x$ & & & & & & & 1 \\
\hline Deloitte and Touche & & & $x$ & $x$ & $x$ & $x$ & & 4 \\
\hline Gartner group & & & $x$ & & & $x$ & & 2 \\
\hline Hiller and Belanger & & & $x$ & $x$ & & & $x$ & 3 \\
\hline Howard & & & & & & & $x$ & 1 \\
\hline Kim and Grant & & & $x$ & & & & $x$ & 2 \\
\hline Layne and Lee & & & $x$ & $x$ & & & $x$ & 3 \\
\hline Lee and Kwak & & & $x$ & & & & $x$ & 2 \\
\hline Moon & & & $x$ & & & & $x$ & 2 \\
\hline Netchaeva & & & & $x$ & & & $x$ & 2 \\
\hline Reddick & & & & $x$ & & & & 1 \\
\hline Shahkooh et al. & & & $x$ & $x$ & & & $x$ & 3 \\
\hline Siau and Long & & & $x$ & $x$ & & $x$ & $x$ & 4 \\
\hline UK National Audit Office & & & $x$ & $x$ & & $x$ & & 3 \\
\hline United Nations & & & $x$ & & $x$ & & $x$ & 3 \\
\hline Wescott & & & $x$ & $x$ & & & $x$ & 3 \\
\hline West & & & & $x$ & & $x$ & $x$ & 3 \\
\hline Windley & & & $x$ & & $x$ & & $x$ & 3 \\
\hline World Bank & & & & & & & $x$ & 1 \\
\hline Sum & 1 & 0 & 20 & 11 & 6 & 8 & 17 & \\
\hline
\end{tabular}

Table 3: the relation of maturity models and the attributes of e-Cohesion $[1,10]$

The analysis shows that only one model focuses on portal functionality since the model of the Commission and Deloitte was especially focused on e-Cohesion functions. Only once encoding is a rather specific feature, it is covered by none of the models. As to the linkages between the models and the seven attributes, 7 models cover only one of them, 5 of them handle two, 11 models focus on three attributes, 2 models cover four and one model handles five of them.

\subsection{Further research and recommendations}

The concept of e-Cohesion is expected to reduce administrative burdens significantly which can be realized by the improvement of the efficiency of fund management procedures. Based on the analysis of the relevant literature the complexity of the identified attributes can be measured either partially or on a one by one basis. Therefore, a model offering a comprehensive assessment of all attributes opens a new and challenging research opportunity. The rationale and motivation of further research is that current model of the Commission and Deloitte already forecasts a significant improvement of efficiency which could be better understood or even extended with a more comprehensive assessment.

What already exists is a specific maturity model, the identified attributes of e-Cohesion and some relevant models that could support the further research. Since the above model is specifically focused on e-Cohesion, its extension is proposed to enable the assessment of all identified attributes. 
Considering the structure of the new model a methodological transformation is suggested, and should be based on a focus area approach. The classical five-level setup cannot be interpreted in case of certain attributes defined by fundamental features of the system architecture (a single one stop shop portal or more portals) or national legislation (application of the only once encoding principle and interoperability to all programmes or in a single programme). These attributes can have a strong impact on efficiency but their character will not be changed as the maturity of eCohesion advances. Consequently the context of measurable attributes is rather complicated so they cannot be addressed by generic maturity levels.

According to the method of measurement of the seven attributes, it is proposed to use the models identified in the previous section as a methodological basis. To focus the scope of models to start with, it is recommended to further analyse the models that address at least three attributes. These models are in alphabetical order: Accenture (3), Almazan and Gil-Garcia (5), Andersen and Henriksen (3), Cisco (3), Deloitte and Touche (4), Hiller and Belanger (3), Layne and Lee (3), Shahkooh et al. (3), Siau and Long (4), UK National Audit Office (3), United Nations (3), Wescott (3), West (3), Windley (3).

Needless to say, the new model must be validated in practice to be theoretically sound and effective, so it shall be based on a strong empirical research among Member States.

\section{Summary and conclusions}

The concept of e-Cohesion is aimed at the provision of e-Government services in order to improve the efficiency of funding procedures in the area of European cohesion policy and rural development policy. These efficiency gains can realize a significant reduction of administrative burdens. In addition to the European legal provisions national regulations can further extend the level of efficiency gains. As a result e-Cohesion can be realized on differentiated stages of maturity as also proven by the study of the Commission and Deloitte. [10] This progress can be best addressed with the methodology of maturity models.

The European Commission and Deloitte made a specific e-Cohesion maturity model but it dominantly focuses on the functionality attribute of e-Cohesion portals. Based on the analysis of eCohesion requirements and the relevant literature seven attributes (portal functionality, only once encoding, interoperability, one stop shop, customer centricity, personalization, e-participation) were identified which are relevant from the perspective of efficiency. Reviewing the pertinent maturity models there is no specific model that can address the complexity of these attributes.

Taking into consideration the high rate of expected efficiency gains there is a room for further research to create a new comprehensive model addressing all identified attributes to develop a better understanding on e-Cohesion. In conclusion, the new model should be the extension of the Commission and Deloitte model and the research shall utilize the methodology of the relevant eGovernment models that address at least three of the identified attributes. 


\section{References}

[1] ABDOULLAH, F., LAILA, C., RAFA, E. A. and ALI, I.: E-Government maturity models: a comparative study (Chapter 3), in: International Journal of Software Engineering \& Applications (IJSEA). Vol. 5, 2014.

[2] ANDERSEN, K. V. and HENRIKSEN, H. Z.: E-government maturity models: Extension of the Layne and Lee model. Government Information Quarterly, 23(2), 2006, p.236-248.

[3] BATÓ, M.: National Regulatory Background for Financial Instruments established from the 2014-2020 ESI Funds - First Experiences in Hungary in European Structural and Investment Funds Journal (EStIF Journal), 4/2016. (Lexxion Publisher, Berlin. 2017, pp. 214-218).

[4] BECKER, J., KNACKSTEDT, R. and PÖPPELBUSS, P.: Developing Maturity Models for IT Management - A Procedure Model and its Application. Business \& Information Systems Engineering 1(3), 2009, pp. 213-222.

[5] BEKKERS, W, VAN STEENBERGEN, M., BOS, R., BRINKKEMPER, S. and VAN DE WEERD, I.: The design of focus area maturity models. In: Winter, R., Zhao, J.L., Aier, S. (eds.) DESRIST 2010. LNCS, vol. 6105, 2010, pp. 317-332, Springer, Heidelberg.

[6] BRUIN, T. DE., FREEZE, R., KULKARNI, U. and ROSEMANN, M.: Understanding the Main Phases of Developing a Maturity Assessment Model. In: Proceedings of the 16th Australasian Conference on Information Systems. Sydney, 2005.

[7] EUROPEAN COMMISSION, Action Programme for Reducing Administrative Burdens in the EU, Office for Official Publications of the European Communities (Pages 3, 8), Luxembourg, 2010.

[8] EUROPEAN COMMISSION, European interoperability framework EIF) for European public services (Pages 1, 2), in: Official Journal of the European Union, 2010.

[9] EUROEAN COMMISSION, Draft opinion of the High Level Group, Administrative burden reduction; priority area Cohesion Policy, second opinion - eCohesion Policy (Pages 3-5), Brussels (2011), Viewed 5 January 2017, [online]. http://ec.europa.eu/smart-regulation/refit/ admin_burden/docs/120430_opinion_ecohesion_en.pdf

[10] EUROEAN COMMISSION, eGovernance study at EU / Member State level, Draft final report by Deloitte, (Pages 14 - 15, 48), Brussels (2012), Viewed 5 January 2017, [online]. http://ec. europa.eu/agriculture/external-studies/2012/e-\%20government/fulltext_en.pdf

[11] EUROPEAN COMMISSION, Regulation (EU) No 1303/2013 of the European Parliament and of the Council (Articles 4, 122, 140), in: Official Journal of the European Union , 2013.

[12] EUROPEAN COMMISSION, Commission implementing regulation (EU) No 1011/2014 (Chapter II.), in: Official Journal of the European Union, 2014.

[13] EUROPEAN COMMISSION, Commission implementing regulation (EU) No 821/2014 (Chapter III.), in: Official Journal of the European Union, 2014. 
[14] LAHRMANN, G., MARX, F., METTLER, T., WINTER, R. and WORTMANN, F.: Inductive Design of Maturity Models: Applying the Rasch Algorithm for Design Science Research. Service-Oriented Perspectives in Design Science Research. Springer. 2010, pp. 176-191.

[15] LAPOSA, T.: E-Cohesion: How to intensify European fund management by electronic services, In: Alexander Balthasar; Blaž Golob; Hendrik Hansen; Balázs König; Robert Müller-Török; Alexander Prosser - Central and Eastern European e|Dem and e|Gov Days 2015, Budapest, 2015.

[16] LAYNE, K. and LEE, J.: Developing fully functional E-government: A four stage model. Government Information Quarterly, 18(2), 2001, p. 122-136.

[17] METTLER, T.: Maturity assessment models: a design scienceresearch approach. International Journal of Society Systems Science. 3 (1/2), 2011, p. 213-222.

[18] NEMESLAKI, A.: The theory of "IT-government" alignment: assessment and strategic fit in Hungary's case, In: Alexander Balthasar; Blaž Golob; Hendrik Hansen; Robert Müller-Török; András Nemeslaki; Johannes Pichler; Alexander Prosser - Central and Eastern European e|Dem and e|Gov Days 2016, Budapest, 2016.

[19] CARAlli, R. A. and MONTGOMERY, A.: Maturity Models 101: A Primer for Applying Maturity Models to Smart Grid Security, Resilience, and Interoperability, Carnegie Mellon University, Software Engineering Institute, Pittsburgh, 2012. 